\title{
Learning Assessment Practices in Ethiopian Universities: Quests versus Upheavals
}

\author{
Firdissa Jebessa Aga ${ }^{1 *}$ \\ ${ }^{1}$ Institute of Educational Research, Addis Ababa University, Addis Ababa, Gulelle 150071, Ethiopia \\ *Corresponding Author: firdissa.jebessa@aau.edu.et
}

(Received: 04/23/2021; Accepted: 12/07/2021; Published: 12/16/2021)

DOI: https://doi.org/10.37906/real.2021.6

\begin{abstract}
This study examined learning assessment practices in universities taking one Academic Unit in Addis Ababa University (AAU), Ethiopian as a case. A qualitative approach was employed to generate data from 20 instructors who were attending a capacity building training at the Academic Unit. Supplementary data were secured by reviewing literatures and guidelines. The results have shown that students' mastery of the learning outcomes (LOs), and achievement of the criterionreferenced assessment requirements were not to the required level. As a result, there were practices of manipulations and invalid subversions of marks bay raising scores without changing the phenomena and without enhancing learning and behavioral change to learners. Moreover, there were no modules designed around competencies with explicit, measurable, and transferable LOs to be assessed. Consequently, the quests and expeditions inherent within the criterion-referenced assessment guidelines were unmet - resulting in matchless upheavals. It has, therefore, been recommended that conscious efforts should be made to make alignments and /or linkages among the salient elements that enhance students' learning with understanding.
\end{abstract}

Keywords: Learning, Assessment, Modules

\section{THEORETICAL AND CONCEPTUAL BACKGROUND OF THE STUDY}

The current highly competitive and continuously evolving learning environments have attracted the interests of many countries towards learning assessment, particularly at universities. This is due to the heightened recognition and need that every student should graduate with the knowledge, understanding, and skills he or she needs to be successful in life and work. This is achieved by competency-based education (CBE), which "...has already shifted dramatically across the landscape of higher education" (Cunningham, Key, \& Capron, 2016:1). Going beyond the traditional systems which advance students based on seat time, often resulting in significant gaps in learning; CBE broadens access to higher education by assessing student-based workforce ready competency.

As Pace and Worthen (2014:1) indicate, the International Association for K-12 Online Learning (iNACOL) and the Council of Chief State School Officers (CCSSO) brought together educators, instructional leaders, and education advocates in 2011 to develop the following working definition for competency education:

a. Students advance upon mastery, not seat time;

b. Competencies include explicit, measurable, transferable learning objectives that empower students;

c. Assessment is meaningful and a positive learning experience for students;

d. Students receive timely, differentiated support based on their individual learning needs; and 
e. Learning outcomes emphasize competencies that include application and creation of knowledge.

The same source (P. 5) went on indicating that "[a] highly trained and engaged educator workforce will be the single most important driver of a successful competency education system". Such an educator may play instructional leadership roles. He/she, thus, should possess achievement - focus and results orientation, and instructional expertise. In line with this thought, an instructional leader is expected to:

a. hold self and others accountable for high academic achievement of all students;

b. create and communicate a clear, compelling vision of high academic achievement and inspire others to fulfill the vision by gaining buy-in and commitment;

c. set challenging goals, and demonstrate persistence and overcome obstacles to achieve the goals; and

d. exhibit commitment to equity and create a sense of urgency to close achievement gaps and prepare all students for college and career success (Hillsborough, n.d.: 1).

Beyond the explicit leadership roles, instructional leaders are also expected to possess instructional expertise so as to:

a. conduct high-quality classroom observations, identify effective teaching practices and understand pedagogy that results in improved student learning;

b. use data to differentiate instructional support and interventions, and support teachers in using data to differentiate instruction; and

c. ensure students mastery standards and attainment of the set LOs by aligning curriculum, instruction and assessment strategies (Ibid).

Instructional leaders, therefore, have different roles under different circumstances and for different batches of students demanding of them new insights, attitudes, and skills to adapt instruction for students with varying levels of competencies and interests. This for Pace and Worthen (2014:5) requires "significant changes to pre-service preparation, certification, professional development, and evaluation programs to ensure educators have the support and resources to make this transition". This in turn calls for aligning "policies and programs that would make it possible to build an education workforce with the expertise to ensure all students master competencies aligned to standards by graduation" (Ibid).

The basic principles inherent within competency-based education and learning entail designing tasks, assignments and examinations which assess a much broader range of competences emanating from graduate profiles with virtues, and abilities inherent within goals within programs in terms of: general competencies (professional/vocational skills), specific competencies (job-specific skills) and transferable skills (such as inquiry skills, critical thinking skills, reflective thinking) and redefining them in order to create a coherent unit of study enabling the learner to perform a certain task or work (AAU, 2014a:24).

A quest for competency education entails focusing on student mastery of critical competencies instead of seat-time requirements that communicate little about the quality of learning. Assessment in a competency education enhances meaningful and a positive learning experience for students by providing them with highly personalized learning pathways to ensure mastery of the academic knowledge, values and skills they will need to succeed in college and careers; and assesses understanding that is both qualitative and quantitative in nature and to provide multiple modalities with which students can demonstrate learning (Pace \& Worthen, 2014; Learning, 2002; Brown \& Knight, 1994).

Realization of CBE, therefore, demands sound practices for the assessment of competency. "The question of competency" for Brown and Knight (1994:27) "is inextricably linked with matters to do with criterion referenced assessment" (CRA). Criterion referenced assessment deals with measuring performances based on mastery of a specific set of standards (or performance descriptors) and/or a set of pre-specified qualities or criteria, and standards by describing the knowledge, understanding, and skills as markers of achieving learning outcomes. CRA, thus, determines reports what students can do, what they 
know, and how well they are doing relative to a pre-determined performance level on a specified set of educational goals or outcomes included in national and institutional curricula. In doing so, CRA focus on individual assessment based on descriptions of performance across a range of levels and results in greater reliability, validity and transparency as opposed to norm-referenced assessment which provides information about an individual's performance against that of others (Green, 2002; Rudner, \& Schafer, 2002; Brown, 1998; Harvey, 2004).

While norm-referenced tests ascertain the rank of students, criterion-referenced tests (CRTs) determine "...what test takers can do and what they know, not how they compare to others (Anastasi, 1988:102). CRTs report how well students are doing relative to a pre-determined performance level on a specified set of competencies.

Instructors at higher education institutions (HEI) are, therefore, expected to design assessment procedures in a way they support learning through student involvement in assessment, prompt feedback, flexible and formative approaches and employ a wide variety of assessment methods so that students ascend the sequence as far as they can (AAU, 2014b:33). It is thus essential to indicate their level of competence in that topic whereby internalized standards of competence, which enable reflective thinking and self-direction, can be developed by self- and peer-assessment (Biggs, 2003:12).

In the spirit of competency-based learning and criterion-referenced assessment, Pace and Worthen (2014) assert that educators need to possess expertise virtues, abilities and skills that will enable them to:

1) provide timely, differentiated support to students based on individual learning needs, moving each student along an individual learning trajectory at a sufficient pace to achieve college and career readiness in time for graduation;

2) align instruction to the explicit, measurable, transferable learning objectives;

3) use formative assessments to regularly assess student progress and readiness to demonstrate mastery on a summative assessment;

4) develop and implement performance-based formative and summative assessments with high validity and reliability;

5) use data on individual student learning in a timely, ongoing manner to inform instruction and support student progress to mastery;

6) support student development of lifelong learning skills and social and emotional competencies; and

7) design and manage personalized instruction, using technology, including blended or online learning, to expand learning opportunities so students can progress to mastery along individual trajectories.

Teacher educators who possess the above virtues, abilities and skills will decently enhance students' intrinsic interest in learning activity resulting in deep learning. Inherent within the intrinsic interest is authentic assessment, which is seen as more practical, realistic, motivating, and yet challenging (Bloxham \& Boyd, 2007; Brown \& Knight, 1994).

Though there are critique against authentic assessment both in terms of how it is being interpreted and in the pragmatic and economic costs of doing it well in the current regulatory framework of higher education, Bloxham and Boyd (2007:29), recognize that the relative freedom of higher education gives more scope for authentic assessment than that exists in schools. As the same source (p. 27-29) indicates, "much of the move towards diversifying higher education assessment is based on the implicit notion of authentic assessment, and higher education has a tradition of using it in various ways, for example on vocational awards".

Inherent within the foregoing discussions is the fact that $\mathrm{CBE} /$ learning has become a means of existence for many higher learning institutions (HLIs) in many countries including Ethiopia and elsewhere. It is seen as an opportunity to enable students achieve the required credits through competency-based assessments. 
Basically, CBE and learning enhance competence building in specific, general, and transferable knowledge, understanding, skills and attitudes ultimately guaranteeing effective living, employability, and success of the graduates. This is because learning at what so ever level enhances students' achievement of the required competencies.

Cognizant of this fact, Ethiopia has put in place curriculum standards, and assessment modalities in which expected learning outcomes are pre-defined and stated in national and institutional curricula. Higher learning institutions in Ethiopia have, therefore, given a serious consideration to competency-based learning and assessment related to LOs (AAU, 2014a; 2014b). Instructors in Ethiopian Higher education Institutions (HEIs) are, therefore, acquainted with competency-based learning and assessment, and modularization through Higher Diploma Program (HDP). HDP is a practice-based training program for teacher educators at higher education institutions in Ethiopia. Basically, HDP has one-year duration whereby teachers attend 2 hours discussion classes for 2 days per week, supplemented with additional classroom observations and secondary school visits for a week or two. Recently, nonetheless, Addis Ababa University has customized the Program to its context by reducing the duration to a maximum of intensive four months by integrating different competencies, truncating redundant topics, and arranging intensive schedules. Assessment is integral part in both cases (the National framework and that of Addis Ababa University). Whereas the National framework on HDP has four modules dealing with 'Reflective Teacher Educator,' 'Developing Active Learning,' 'Improving Assessment,' and 'Action Research, Making a Difference' (MoE 2006); that of AAU has five modules dealing with Understanding Higher Education, Modularization and Modular Curriculum, Managing Learning and Assessment, Subject Area Teaching, and Action Research and Field-based Learning (AAU, 2014a).

Particularly, Module three on Managing Learning and Assessment presents basic elements of assessment with assessment rationales, principles, methods, importance and grading procedures. Instructors are, therefore, aware of assessment practices and tenets.

AAU (2014a:58) suggests that a variety of assessment methods should be designed to satisfy all LOs. In designing or redesigning modules, it is, therefore, vital to identify and reach at a consensus by instructors and academic leadership on appropriate parameters of assessment; and decide which can be left to individual teachers or subject coordinators. Concerning the general provisions on examinations, AAU (2019: 78 [Article 82, No. 821]) indicates that:

Student learning shall be assessed on a variety of ways/continuous assessment in the form of tests, assignments, presentations, etc. to determine the final grade earned. This shall account for $50 \%$ of the total module/course grade. The remaining $50 \%$ shall be allotted for a final exam conducted at the end of module/course delivery. Instructors shall monitor the student's academic performance by keeping track of records.

The same document (No. 82.4) further indicates that:

A module...as a matter of routine, shall include information on components of continuous assessment providing the distribution of grade points with a performance assessment criterion among various types of exams and other works in percentage terms. A copy of the module/course outline shall be submitted to the academic unit concerned at the beginning of each course and shall be distributed to students upon approval by the department.

In the same vein, AAU (2014 a: 35-36) presents the following points concerning the assessment of the modular curriculum:

1) performance of learners in a module should be evaluated in relation to the achievement of the modularobjectives (criterion-referenced) rather than on competitive basis (norm-referenced) and normal distributions; 
2) the old system of using the normal curve for determining grades should be replaced by initial planning of correspondence between number-grades and letter-grades while determining the latter;

3) failing grades for a module can be determined by learner performance below 60 percent of the total. it is suggested, however, that each instructor with the consultation of his/her department can modify the suggested grading scale;

4) assessment of student work should be continuous, valid, and reliable; and

5) there should be a meaningful and effective system of evaluating, revising, upgrading or phasing out academic programs (AAU, 2014 a: 35-36).

Overall, many of the available national and institutional curricula documents and/or guidelines advocate that students achieve the requirements set out in criterion-referenced assessment modalities, and master the LOs which are inherent within the modalities, and achieve learning with understanding. These in turn call for the alignment of competency-based outcomes and learning activities with assessment; and intentionally designing curricula around competencies with explicit, measurable, transferable LOs and integrate with instruction, and assessment. The needs for the said alignment, design and integration have come with the growing body of research into higher education assessment on which academics, leaders and policy makers can begin to build robust policy and practice decisions (Bloxham \& Boyd, 2007:15). Equally, we are witnessing that universities are becoming accountable for the quality of their assessed graduates. Universities are no longer remote, 'ivory towers', and can no longer be regarded as "diarchies" whereby institutional autonomy and academic freedom seem to obscure accountability for inefficiencies including poor assessment practices.

\section{PROBLEM STATEMENT}

Our age is witnessing the need for quality learning whereby students achieve learning with understanding by mastering the requirements set out in criterion-referenced assessment modalities. Prevailing practices, nonetheless, show that there are distortions and confusions in assessment of learning - sending wrong signals to students that they inclined to learn what they think they will be tested on. The practice in which assessment determines what and how students learn more than the curriculum does has a backwash effect. Similarly, a poorly aligned and unintegrated system - where the test does not reflect the learning outcomes set out will result in inappropriate surface learning (Biggs, 2003; Brown \& Knight, 1994).

Equally, assessment tasks may not be assessing what they are supposed to assess. They may be assessing lower-level understanding of the material, and may be failing to assess the stated outcomes of a program of study. Similarly, anxiety-provoking assessment is associated with a surface approach to learning by students (Bloxham \& Boyd, 2007).

Moreover, each of the different purposes of assessment emphasizes different principles and is hindered by others. Consequently, there are dilemmas and tensions that the different purposes of assessment create needing resolutions. Bloxham and Boyd (2007) highlight the conflicting varying purposes of assessment leading to juggling the different intentions of assessment, concentrating on some purposes over others-all of which can distort the value of assessment in universities. Paying attention to neglected purposes helps pinpoint where our enhancement efforts should lie.

Inherent within the foregoing discussions is the fact that there is a conflicting nature of established principles underlying sound assessment practices and consequently assessment problems haven't gone away. By implication, there is a dire need to examine integration level of curricula, instruction, and assessment to promote learning with understanding; and the way item quality and fair distribution are assured as per difficulty levels in assessment practices in Ethiopian universities. 
Paradoxically, nonetheless, the concerns about the assessment system are not widely shared among stakeholders. As a result, "assessment is still not the high-profile issue which it should be, given the argument that is assessment arrangements which determine the curriculum in action." (Brown \& Knight, 1994:46).

It is, therefore, my conviction that assessment research serves as a basis for enhancement of assessment practices. Enhanced assessment practices in turn heightens the quality and amount of learning achieved by students, and serves as intrinsically motivating factor for students and lead to better retention of the competencies which they can apply in other settings (Bloxham \& Boyd, 2007). The need for the study was, therefore, born out of the intuited doubts on the alignments of the required elements set out in competencybased learning and criterion-referenced assessment modalities to enhance learning with understanding.

\section{OBJECTIVES OF THE STUDY}

The study aimed at assessing whether students achieved the requirements set out in criterionreferenced assessment modalities, and the extent to which competency-based outcomes and learning activities were aligned to assessment. More specifically, the study intended to achieve the following objectives.

1) To assess whether or not students achieved mastery of the LOs which are inherent within criterionreferenced assessment modalities;

2) To examine the extent to which competency-based outcomes and learning activities were aligned with assessment to promote learning with understanding;

3) To gauge the extent to which modules were intentionally designed around competencies with explicit, measurable, transferable LOs to be assessed, and are integrated with instruction, and assessment; and

4) To identify salient challenges faced /witnessed in assessment practices at universities in Ethiopia.

\section{BASIC RESEARCH QUESTIONS}

To achieve the above objectives, the study tried to answer the following questions.

1) Do students achieve the requirements set out in criterion-referenced assessment modalities?

2) To what extent competency-based outcomes and learning activities are aligned to assessment to promote learning with understanding?

3) To what extent modules were intentionally designed around competencies with explicit, measurable, transferable LOs to be assessed?

4) What are the salient challenges faced /witnessed in assessment practices at universities in Ethiopia?

\section{THE RESEARCH METHODOLOGY}

The study utilized a qualitative approach. Semi-structured open-ended questionnaire was used to generate data from 20 instructors who were attending an in-house capacity building training at one Academic Unit in Addis Ababa University (AAU), Ethiopia. The Academic Unit which has been taken as a case runs Bachelors, Masters and PhD programs. For the sake of anonymity as part of ethical considerations, nonetheless, the name of the Academic Unit has not been mentioned. Whereas the rationale for taking the case Academic Unit was convenience as the participants were attending a training in one room, the rationale for taking AAU was purposive. AAU is the oldest and the largest learning institute in Ethiopia with a mandate of producing high level trained man power mainly for the emerging HEIs in Ethiopia. As a result, whatever practiced in AAU is also replicated in other HEIs including sharing experiences and resources. Instructors from AAU also frequently go to the others as guest lecturers, speakers and assessors. The fact that AAU is situated at the center of the capital city of the country also makes it appropriate to represent the rest of the HEIs in the country. 
Other than these, course outlines of five instructors and teaching materials of three instructors were collected and scrutinized, both from the same Academic Unit, so as to identify whether the University was actually implementing Modular curriculum and competency-based contents or not. Moreover, supplementary data were secured by reviewing extant literatures, national and institutional documents and guidelines. Whereas the literature review was guided by purposively formulated themes/objectives, the questionnaire was based on open-ended questions, which are intended to generate supplementary data. In both cases the themes that guided data collection focused on whether students achieved the requirements set out in criterion-referenced assessment modalities; the extent to which competency-based outcomes and learning activities were aligned to assessment, and the extent to which modules were intentionally designed around competencies with explicit, measurable, transferable LOs to be assessed; and identifying salient challenges in assessment practices.

As soon as twenty copies of the questionnaire were collected, Codes were given to all of them (R1, R2, R3...R20) mainly to maintain the anonymity of the respondents. The data collected by using the reviews and questionnaire were qualitatively analyzed under pertinent themes highlighted above.

\section{ANALYSES, DISCUSSIONS AND RESULTS}

From the 24 copies of the questionnaire dispatched to instructors at the Academic Unit, 20 (83\%) were properly filled in and returned. Of the 20 respondents, there were only 3 females. Regarding their teaching experiences, the majority (40\%) had above 10 years; whereas $30 \%$ and $15 \%$ were $3-6$, and 7-10 years of experience respectively. Equally, 15\% had under 3 years of experience in teaching. Qualification wise, whereas the majority (40\%) were Doctorate Degree holders, 35\% and 25\% were, respectively, Master's and Bachelor's degree holders.

When the rank of the respondents is seen the majority were associate professors. More specifically, $30 \%$, $25 \%, 20 \%, 15 \%$, and 5\% were respectively associate professors, lecturers, assistant professors, assistant lecturers, and senior technical assistants. There was only one professor within the respondents.

Other than the data generated through the open-ended questions, course outlines of five instructors, and teaching materials of three instructors - all from the same Academic Units were collected and scrutinized. In the sub-sections that follow, therefore, analyses, discussions made, and results have been presented one after the other.

\subsection{Students' level of achievement of the requirements set out in criterion-referenced assessment}

A question was presented to the respondents on issues related to the extent to which students had achieved the requirements set out in criterion-referenced assessment modalities. The respondents had the feeling that students' achievement of the requirements set out in criterion-referenced assessment was not to the required level. Basically, students' achievement of the requirements would manifest the students' enhanced learning with understanding. The prevailing practices, nonetheless, prove the reverse.

The requirements set out in criterion-referenced assessment modalities would align with learning outcomes (LOs) to ascertain mastery of learning. The students' mastery and/or achievement of the LOs, was, nonetheless, questionable. As R10 indicated, "Mastery of the LOs cannot be achieved by students in Ethiopian universities due to the level of learning provided, assessment practiced, and other inhibiting factors". It was also commented by $75 \%$ of the respondents that the assessment practices and item quality were questionable as their preparations were random and unsystematic.

Related to the issue under discussion, a question was presented to the respondents on the extent to which assessment practices have enhanced learning with understanding. It has been learnt that "assessment practices' enhancement of learning with understanding is very unlikely" (R5, R11). Almost all the respondents have the view that the assessment practices could barely enhance learning with 
understanding. Fourth-three percent (43\%) of the respondents attributed the reasons to the following factors:

a. Some instructors' teaching practices encourage surface learning whereby students memorize the contents and answer exams/tests without deep understanding;

b. some students copy assignments from their friends and submit without understanding of what they have written;

c. some students learn for assessment rather than for understanding;

d. the assessment practices might not result in practical deep learning and understanding of the learning outcomes; and

e. very few students achieve mastery to the required level of learning as a result of which very few of them achieve the criterion referenced requirement set in the guidelines such as Senate Legislation, and HDP Modules.

As a follow up to the above issues, a question was raised on how the instructors used to manage the students' assessment and/or to cop up with the prevailing assessment-related drawback practices. The trends show that there were practices of manipulating marks to meet the criterion-referenced assessments modalities. Thirty-two percent (32\%) of the respondents indicated that there were practices of scaling up of marks (by some instructors) when:

1) a fairly large number of students score comparatively low points (R1, R5, R13, R17);

2) none of the students achieve ' $A$ ' grade, that is when many and/or all fail to score above $90(A+)$, Above 85 (A), 80- 84.9 (A-). 75-79.9 75-79.9 (B+) (R6, R17);

3) most of the students score low marks and tend to fail when evaluated based on the criterion-references assessment requirements (R1, R8, R13); and

4) the majority of the class underperform and there seems to exist a need to minimize the number of the failures and the consequent dropout rate (R7, R11, R20).

The cases show that there were practices of manipulating marks to meet the criterion referenced assessment requirements by:

1) adding some marks as bonus to bring students achieve above 85 (A) marks and make students happy as a result of which the instructors would be praised of their teaching performances that might be attributed to the number of $A$ students;

2) conducting probability density of the normal distribution);

3) resetting grading system based on students' class performance on that particular year (R5), the practice of which is norm-referenced assessment as opposed to the required criterion-referenced assessment;

4) just adding some marks to push the highest mark to score Grade A+/A, then the others follow the suit;

5) adding extra marks to the level that the highest scores get 85 , or to increase the mark weights to the level that most students pass or score high marks; and

6) adding small marks (such as 5) to all students, if many students fail thinking that the exam was very difficult.

Furthermore, one respondent reiterated his practices on the issue:

I would look into the students' class activities when I observe needs, I would add some marks for active students and less marks for less active students. Besides I [give] open and optional assignments to all students so that interested students would submit the assignment, on the basis of which I add some marks to the students' who had submitted the assignments (R9).

This shows that the instructors' assessment practices and/or methods did not discriminate learners based on mastery of the requirements towards achieving LOs. As Bloxham and Boyd (2007:27, citing 
Ramsden, 2003, and Struyven et al., 2002) indicate, “...research suggests that tutors do need to be mindful that their assessment methods may not be as discriminating as they hope they are and may permit students to pass with 'conceptions of subject matter that teachers wished to change' or to avoid large sections of the curriculum.

\subsection{Alignment of curriculum, instruction, and assessment}

A question on the extent to which instructors integrate curriculum, instruction, and assessment to promote learning with understanding was presented to the respondents. Whereas there were mixed feelings and varying levels of understanding of the issue, the sought alignment for the purpose was said to be almost nonexistent. One respondent indicated that "integration of curriculum, instruction, and assessment was nonexistent due to the fact that random assessment questions are set, not in accordance with the learning outcomes" (R15). The same respondent added that "an alignment of competency-based outcomes and learning activities with assessment is what is required but not practiced".

Such a practice, therefore, negatively affected the level of learning with understanding, as rated "Low" by three respondents (R5, R12, and R19). In the same vein, (R6) indicated that "Practically... teachers rarely integrate curriculum, instruction, and assessment to promote learning with understanding".

As a continuation of the issue of alignment, availability of conscious efforts to distribute assessment items in accordance with difficulty level was raised to the respondents. Though theoretically it is said that distribution of assessment item is in accordance with difficulty levels, practically, nonetheless, in most cases instructors assigned marks to exam questions randomly just based on the total marks given for the exam. One of the respondents indicated that "we are witnessing from many instructors who were assigning the same mark distribution for very simple questions, which can be done within 10 minutes and somehow difficult questions, which can be done within 30 minutes" (R14). This shows that very little conscious efforts were made to distribute assessment items and their values in accordance with difficulty levels.

\subsection{Availability of Designed Modules}

A question on the extent to which modules were intentionally designed around competencies with explicit, measurable, transferable LOs to be assessed was presented to the respondents. Whereas some of the respondents reiterated their respective teaching materials as Modular curriculum, a further scrutiny has revealed that there was no proper module prepared as it ought to be. It was in contravention to the documents of the Federal Ministry of Education of Ethiopia and the Addis Ababa University that were claiming as if Modular curriculum had been implemented in all the universities in Ethiopia since 2009. The available practices appeared paradox demanding critical solution as it caused the prevailing assessment irregularities (R11). Available teaching materials were not designed for competency-based learning, rather just to make the lecture easy (R4). They commonly agreed that the courses were not designed as per the requirements of any Module development. On top of this, different respondents indicated:

1) It is difficult to say what I have been giving to my students as a module (a complete material, I just give the students the lecture notes). As per my current understanding, the lecture note won't satisfy the criteria for a module (R2);

2) Poor Modules/teaching Materials design. Not competency based... design (R5);

3) As far as I know I did not see any module for the course I teach. I just follow some reference materials as textbooks (R13);

4) There is no proper Module material prepared formally, demanding critical solution (R11); and

5) Modules' integration of assessment into daily instruction and classroom activities "is very unlikely (R11). 
Further attempts were made to see into the teaching materials that were considered as Modular curricula by collecting from three instructors at the case Academic Unit and securitizing their contents. Consequently, it has been learnt that whereas the covers of the materials read as: "Modular Curriculum for XXXX," scrutiny of the contents of those materials showed that they were actually syllabi not modular curricula. They were not designed in a way that "self-contained, self-instructional package, self-paced learning according to student needs and abilities" (AAU, 2014a: 8).

Overall, it has been learnt that practically, very little conscious efforts have been made to intentionally design modules/teaching materials around competencies with explicit, measurable, transferable LOs to be assessed. The National assumptions and the provisions within AAU's Legislation has not been met as almost all the Modules were not in true sense, rather their contents were almost that of syllabi as they just present summary outlines of the elements required to develop modules and/or teaching materials.

\subsection{Challenges in Assessment in Ethiopian HEIs}

Requested to tell salient challenges in assessment at Higher Education Institutions (HEIs) in Ethiopia in general and at their Academic Units in particular, almost all the respondents agreed that shortage and/or lack of pertinent and well-prepared module and dynamic learning resources have directly or indirectly affected the learning assessment practices.

More specifically, as there were no well-designed modules for each course, instructors were said to be forced to use just syllabi, published books, and course outlines and consequently there was no uniformity of assessment practices on the same courses with different instructors. The case was exacerbated with the fact that there was shortage of qualified and experienced academic staff with assessment knowledge, understanding and skills (R7, R11, R18, and R19).

Moreover, five respondents (R3, R9, R15, R16, and R19) identified shortages of the learning resources including: laboratory facility/equipment, field practices, printer, projector, white board, and workshop accessories that may support teachers to upgrade their performances. The respondents had the view that with the prevailing shortages, bringing students to the required criterion-referenced grading level, and to ascertain learning with understanding would be a challenging task for the instructors

Based on the respondents' repeated concerns, the challenges have been categorized under leadership and/or policy related, student related and instructors related issues.

a. Among the leadership and/or policy related challenges are:

b. Large number of students per class (large class size),

c. Office politics,

d. Lack of test banks,

e. Space for classroom and office,

f. Lack of properly designed modules, and

g. Zero Attrition Principle, and pressurizing staff to give no failing grades to students were among the leadership and/or policy-related challenges in assessment at HEIs in Ethiopia.

One respondent added on the first point (number of students) that "due to the high student-teacher ratio, it is difficult for properly incorporating feedback into the overall assessment practices so as to enhance deep learning" (R12). Moreover, another respondent added on the last point that "a couple of graduate assistants were complaining about one or two top management personnel forcing (and threatening) them to give 'A's to some specifically identified students" (R6).

Whereas Brown and Knight (1994:147) have the belief that "...a constraint on innovation reform which is potentially far more serious is Modularization", in Ethiopian case, the results have shown that Modularization has not been formally designed in its true sense. 
Student-related challenges in assessment also include:

a. Lack of motivation and interest for learning,

b. Students come to class without being prepared,

c. Students self-learning is poor (further reading) and fear of challenges and assignments,

d. Cheating,

e. Not-so-matured and competent students joining the Postgraduate program (PGP),

f. Student readiness for teaching and learning is questionable, and

g. Students copy laboratory reports from other students.

It was also commented by one respondent that "students consider a university setup a simple extension of secondary schools. They do not exert effort to achieve the required assessment requirements and learning outcomes for the level" (R3).

Finally, staff- related challenges in assessment include:

a. Instructors' lack of assessment background, knowledge, and skills;

b. Low or no motivation to enhance deep learning;

c. Late class begging;

d. Lack of timing assessment;

e. Poor test development vis-à-vis curricula; and

f. Lack of skills and personality guts to motivate students to get prepared for proper authentic learning and assessment.

Staff- related assessment challenges appear critical as staff are frontline implementers and driving forces for success in any innovation including that of assessment. As Brown and Knight (1994) indicate, "One of the main barriers to innovation in assessment will be academic staff" (p.142). These authors went on rationalizing their assertions:

Some will not see the need; some will be wary of the purposes and implications of change; while others will simply lack the technical knowledge to move from the rhetoric which they accept to the reality which needs to follow. 'Managing academics is like herding cats', it is said. There is, then, a substantial, hopefilled, staff development job to be done (Ibid).

It was also commented by five respondents that Students (including in PGPs) were flooded with PowerPoint slides. They rationalized their comments to the fact that it would be difficult to prepare students to achieve higher level competencies that may require inquiry, discovery, explorations, synthesis, and decision-making skills. The respondents attributed their points to the fact that the practices affect students' readiness for proper assessment practices.

As a continuation of the open-ended questions, five respondents had the view that overlapping and/or close conceptions among the terms such as: learning outcome, objectives, competencies, achievements and skills added confusions and challenges to assessment practices. In the same vein, there are also learning outcomes related consternations that may add challenges in assessment at HEIs. Synthesizing from different sources, Bloxham and Boyd (2007:28) present criticisms of LOs in a way they affect assessment practices:

a. they may appear fuzzy and messy business to clearly specify learning and teaching;

b. it may be difficult to write in a meaningful way and have to be interpreted in relation to the context, which can only be done by those who are already familiar with that context;

c. they may ignore the unpredictable and indefinable aspects of learning, the 'emergent outcomes';

d. they may reduce the value of subject content compared with skills,

e. they may restrict learning as students focus on what is needed to pass in assessment; 
f. they may be written in general terms using a broader description of outcomes, including skills, knowledge and understand rather than detailed lists of competences in higher education.

In addition, Jackson (2000) points further criticisms, some more practical than educational, such as the time needed to prepare staff for the LOs approach to course design and teaching, the bureaucracy, and the threat to professional autonomy contained in the requirement to make explicit what has been implicit. Whereas Biggs (2003) indicates that the nature of higher-order outcomes does not discourage unforeseen or unforeseeable outcomes because they tend to specify the process the student should demonstrate, rather than the detailed content; practices show that instructors do not dare going beyond the stated learning outcomes.

\section{SUMMARY, CONCLUSIONS, AND RECOMMENDATIONS}

\subsection{Challenges in Assessment in Ethiopian HEIs}

Analysis and discussions made so far have shown that students' mastery of the LOs, and achievement of the requirements set out in criterion-referenced assessment modalities were not to the required level. Consequently, there were practices of manipulating marks to meet the criterion-referenced assessment modalities. Some instructors engaged in scaling up grades by: a) adding some marks to push the highest mark to score Grade A+/A, then the others follow accordingly; b) conducting probability density of the normal distribution; and c) resetting grading system based on student's class performance on that particular year.

Moreover, alignment of curriculum, instruction, and assessment to promote learning with understand was almost nonexistent due to different reasons one of which was randomly setting assessment tools. Alignment of competency-based outcomes and learning activities with assessment was, therefore, said to be nonexistent. Teachers, therefore, rarely integrate curriculum, instruction, and assessment to promote learning with understanding. It has also been learnt that there were no proper modules materials prepared. The available teaching materials were not designed for competency-based learning and assessment following module design formats.

Finally, there were a number of interactive leadership and/or policy-, student- and instructors- related challenges in Assessment at HEIs. They have directly or indirectly affected the learning and assessment practices at the HEIs in the country.

\subsection{Conclusions}

The purpose of this study was to assess whether students achieved the requirements set out in criterionreferenced assessment modalities, and the extent to which competency-based outcomes and learning activities were aligned to assessment, and to identify salient challenges in assessment in Ethiopian universities.

The results have shown that there were considerable dissatisfactions with what was being practiced regarding assessment in Ethiopian HEIs in general and at the Academic Unit in particular. The cumulative of such dissatisfactions prove that the assessment practices hardly impact on the students' learning quality and/or learning for understanding.

It can, therefore, be concluded from the results that very little conscious efforts were made to align competency-based outcomes and learning activities with assessment in Ethiopian HEIs. As a result, students hardly achieved the requirements set out in criterion-referenced assessment modalities, and consequently there was no assurance whether the assessment practices enhanced learning with understanding or not. 
In addition, although there are commotions to implement the assessment policies inherent within the national and institutional documents, the practices, however, show that there was no way of assuring item quality and fair distribution of assessment tools maintaining difficulty levels. Worsening the situation, there was a practice of manipulating marks before grading by invalid subversions bay raising scores without changing the phenomena and without bringing vale addition (without enhancing learning and behavioral change) to learners. As Brown and Knight (1994:18) indicate, “...learners' scores can be manipulated easily by subtly adjusting task demands without teaching any differently. Where there is no discriminating power of assessments, students may achieve high grade just with few conceptions of the subject matter and/or teachers themselves may avoid large sections of the curriculum just to enable students get pass and/or over grade (Struyven et al. 2002, cited in Bloxham \& Boyd, 2007).

The assessment tools' connection to curriculum, instruction and learning activities were critical areas of further exploration. Though course outlines bear explicit LOs that would empower students for learning with understanding; very little conscious efforts were made to assure alignment of assessment tools with Los.

It is, therefore, possible to derive implications that there is no way to assure that the assessment practices realized ideas and ideals within policies in such a way that students' voices and choices, authentic learning experiences, and personalization that focus on student success are taken care of or not; and whether the practices actualized the fact that education is life itself, rather than preparation for life.

The fact that there were no modules/self-contained learning materials which are intentionally designed around competencies with explicit, measurable, transferable LOs to be assessed, implies that the assumptions, ideas and ideals within the national and institutional documents have not been met. Overall, the results have shown that competency-based learning and assessment are left at popularization and paperwork without systemic design, structure, and implementation by empowering frontline implementers with preparation, on job-training, and support to excel in a meaningful manner. These all implies that "assessment tasks should be designed to encourage good quality, 'deep' approaches to learning in the students" (Bloxham, \& Boyd, 2007:40).

\subsection{Recommendations}

Teachers today, perhaps more so than ever before, have a need to be knowledgeable consumers of test information, constructors of assessment instruments and protocols, and even teachers about testing. (Rudner \& Schafer, 2002: i)

Based on the conclusions made so far, it has been recommended that the Universities in Ethiopia need to put in place an assessment system that results in mastery of LOs and deep approaches to learning for understanding. In designing their assessment strategies, the universities need to be aware of the different purposes and principles of assessment and the need to achieve balance in assessment. More specifically, universities in Ethiopia, in collaboration with the Ministry of Science and Higher Education, should exert conscious efforts to:

1) align competency-based outcomes and learning activities with assessment practices;

2) enhance students' achievement of the requirements set out in criterion-referenced assessment modalities;

3) put in place modules with explicit, measurable, transferable LOs, activities, and assessment procedures that empower students for learning with understanding; and

4) connect assessment tools to curriculum, instruction and learning activities in a way that learning with understanding can be heightened. 


\section{REFERENCES:}

Addis Ababa University [AAU] (2019). Addis Ababa University Senate Legislation (available at file://C:/Users/user/AppData/Local/Temp/AAU\%20Senate\%20Legislation\%20of\%202019.pdf)

AAU (2014 a). Higher Diploma Program: Module two: Modularization and Modular Curriculum (Up)

AAU (2014 b). Higher diploma Program: Module Three: Managing Learning and Assessment (Up) Anastasi, A. (1988). Psychological Testing. New York: MacMillan.

Biggs, John (2003). Teaching for Quality Learning at university (2nd. Ed.). UK: The Cromwell Press

Bloxham, Sue; and Boyd, Pete (2007). Developing Effective Assessment in Higher Education: a practical guide. England: Open University Press.

Brown, Sally; and Knight, Peter (1994). Assessing Learners in Higher Education. London \& Newyork: RoutledgeFalmer.

Cunningham, J., Key, E.; and Capron, R. (2016). An evaluation of competency-based education programs: A study of the development process of competency-based programs.

https://doi.org/10.1002/cbe2.1025 